Article

\title{
Eco-Friendly Chitosan Production by Syncephalastrum racemosum and Application to the Removal of Acid Orange 7 (A07) from Wastewaters
}

\author{
Anabelle C. L. Batista ${ }^{1,2,3}$, Marta C. Freitas Silva ${ }^{3, \dagger}$, Jefferson B. Batista ${ }^{4, \dagger}$, \\ Aline Elesbão Nascimento ${ }^{3, \dagger}$ and Galba M. Campos-Takaki ${ }^{3, \dagger}, *$ \\ 1 Rede Nordeste de Biotecnologia (RENORBIO), Universidade Federal Rural de Pernambuco, \\ Rua Dom Manoel de Medeiros, s/n, Dois Irmãos - 52171-900 Recife, PE, Brasil; \\ E-Mail: abatista@ufersa.edu.br \\ 2 Departamento de Ciências Animais (DCAN), Universidade Federal Rural do Semi-Árido, \\ Av. Francisco Mota, 572-Costa e Silva—59625-900 Mossoró, RN, Brasil \\ 3 Núcleo de Pesquisas em Ciências Ambientais (NPCIAMB), Universidade Católica de Pernambuco, \\ Boa Vista 50 050-590 Recife, PE, Brasil; E-Mails: martacfs@yahoo.com.br (M.C.F.S.); \\ elesbao@unicap.br (A.E.N.) \\ 4 Instituto Federal de Educação, Ciência e Tecnologia da Paraíba, Av. $1^{\circ}$ de Maio, \\ Jaguaribe 58015-430 João Pessoa, PB, Brasil; E-Mail: biojef13@yahoo.com.br \\ $\dagger$ These authors contributed equally to this work. \\ * Author to whom correspondence should be addressed; E-Mail: galba_takaki@yahoo.com.br; \\ Tel.: +55-81-2119-4017; Fax: +55-81-2119-4043.
}

Received: 19 March 2013; in revised form: 2 May 2013 / Accepted: 25 June 2013 / Published: 1 July 2013

\begin{abstract}
Due to the existence of new methodologies that have reduced the production costs of microbiological chitosan, this paper puts forward the use of agro-industrial residues in order to produce microbiological chitosan and to apply chitosan as an innovative resource for removing acid orange 7 (AO7) from wastewaters. The best culture conditions were selected by a full $2^{4}$ factorial design, and the removal of the dye was optimized by a $2^{3}$ central composite rotational design. The results showed that corn steep liquor (CSL) is an agro-industrial residue that can be advantageously used to produce microbiological chitosan with yields up to $7.8 \mathrm{~g} / \mathrm{kg}$ of substrate. FT-IR spectra of the product showed typical peak distributions like those of standard chitosan which confirmed the extracted product was chitosan-like. The efficiency of removing low concentrations of
\end{abstract}


AO7 by using microbiological chitosan in distilled water (up to 89.96\%) and tap water (up to $80.60 \%$ ) was significantly higher than the efficiency of the control (chitosan obtained from crustaceans), suggesting that this biopolymer is a better economic alternative for discoloring wastewater where a low concentration of the dye is considered toxic. The high percentage recovery of $\mathrm{AO} 7$ from the microbiological chitosan particles used favors this biopolymer as a possible bleaching agent which may be reusable.

Keywords: microbiological chitosan; acid orange 7 (AO7); central composite rotational design; agro-industrial residues; Syncephalastrum racemosum; corn steep liquor; coagulation-flocculation

\section{Introduction}

Among the polymers most investigated today, there is chitosan, a polysaccharide formed by glycosidic amino residues of $\beta$-(1-4)-2-amino-2-deoxy-D-glucopyranose, which is obtained by deacetylation of $\alpha$ - or $\beta$-chitin found mainly in the shells of crustaceans and mollusks, respectively [1], or by the specific action of the enzyme chitin deacetylase (EC 3.5.1.41) on the residues of $\gamma$-chitin present in the cell walls of fungi [2-4]. Among the chitosan-producing fungi, emphasis is given to the class Zygomycetes [4-10], as the species Syncephalastrum racemosum has great potential for producing chitosan in low cost culture media [11].

Currently, chitosan is produced from $\alpha$-chitin, because the production values are commercially advantageous. However, obtaining chitosan from $\alpha$-chitin requires some care regarding standardizing the product [12,13] and incorporating this biopolymer into production lines of different biotechnological areas. In addition, this method of obtaining chitosan has adverse environmental implications as it produces millions of gallons of acidic and basic residues, which are then discharged into the environment, usually without treatment and without a view to re-use [14].

Given this situation, obtaining chitosan by submerged culture of fungi has the advantage of manipulating and standardizing specific physicochemical characteristics, thus facilitating its incorporation into industrial production lines, besides helping to reduce the environmental waste generated when producing chitosan from the deacetylation of $\alpha$-chitin $[11,15,16]$. Nowadays, the acquisition of chitosan from fungal strains has emphasized the use of industrial wastes as an alternative nutritional source for obtaining a byproduct of high value added [6,7,11], and it has been claimed that this leads to a decrease of 38 to $73 \%$ in the total production costs [17].

The great interest in producing chitosan is justified by its potential in biotechnological applications, especially with regard to using it in medical and environmental areas [18-22]. In the environmental area, especially regarding the removal of dye from textile effluents, chitosan has proved that it can remove a high amount of azo dyes [19,23-25] in particular by the method of coagulation-flocculation, where the chitosan acts as a polyelectrolyte which has no potential environmental polluter. Despite the efficiency of this method, it is important to emphasize that the treatment of wastewater tends to be most effective, easy and inexpensive if carried out on the site of the plant site that is producing 
pollutants, because, after reaching the effluent, the dye can interact with other molecules in the environment and this results in expensive procedures for identifying and removing specific dyes.

With the increase in textile consumption and interest in diversifying colors, industries have increased the use of color additives in the production of clothing, for example acid orange 7 or Orange II (AO7). AO7 is a synthetic acid dye that is toxic at a concentration of $0.011 \mathrm{mg} / \mathrm{mL}$ as expressed by the acute toxicity test $\mathrm{EC}_{50}$.

Thus, due to the need to reduce the costs of production and enhance the efficiency of fungi in producing chitosan, this paper assesses the interactive influence of different factors (nutritional source, initial $\mathrm{pH}$ of culture, temperature of incubation and inoculum size) by a full factorial design and applying chitosan as a coagulant agent of azo dye acid orange 7. Despite there already being extensive knowledge of the mechanisms of interactions between chitosan and azo dyes, this study innovates by applying a $2^{3}$ Central Composite Rotational Design (CCRD), with four central points, to evaluate the simultaneous effect of chitosan concentration, dye concentration and $\mathrm{pH}$ on effluent decolorization by coagulation-flocculation.

\section{Results and Discussion}

\subsection{Effects on Chitosan Production}

The simplest and most effective statistical method for analyzing different factors that can interfere in the response to a product is a full factorial design [26], since this enables the possible main effects for the factors analyzed in a specific situation to be estimated. In this study, the nutritional source, the initial $\mathrm{pH}$ and the temperature of incubation were considered as important factors for reducing the production costs and enhancing the productivity of chitosan. Corroborating the studies by BartnickiGarcia and Nickerson [27], the size of the inoculum did not influence the amount of microbiological chitosan produced, independent of the influence of the variables studied.

In our study, the CSL which was used as the sole source of carbon and nitrogen in batch positively influenced the microbiological production of chitosan. This fact may have occurred due to high concentrations of nitrogen (17.57\%) and carbohydrate (13.03\%) found in the CSL concentrate used in this research. The results corroborate those in the literature, which also describe the use of CSL as a good source of nitrogen for the production of biopolymers [7,17,28]. The discrepancy between the values of the nutritional compositions of the CSL concentrate used may have occurred due to the origin of the maize.

The experimental design used to analyze the main effects between the independent factors (the concentration of CSL, initial $\mathrm{pH}$, temperature and size of the inoculum) on the microbiological production of chitosan showed that the best assay occurred when the dilution of concentrated CSL was only $2 \%(\mathrm{v} / \mathrm{v})$, with initial $\mathrm{pH} 8.0,25^{\circ} \mathrm{C}$ and an inoculum size of $10^{2}$ spores $/ \mathrm{mL}$. For these conditions, chitosan was produced at $62.44 \mathrm{mg}$ per gram of dry biomass, or $7.8 \mathrm{~g}$ of chitosan per kilogram of CSL concentrate. This result was superior to the results of Wang et al. [7], who obtained a yield of $6.12 \mathrm{~g}$ of chitosan per kilogram of substrate concentrate (CSL + molasses) using Absidia coerulea. This fact corroborates the literature which describes $S$. racemosum as a good producer of chitosan in different nutritional media [11]. 
As described by Aranaz et al. [29], the applicability of chitosan is dependent on its physico-chemical properties. For this reason, analyses were performed to characterize the chitosans, and showed a deacetylation degree $(\mathrm{DD})=88.14 \%$ for microbiological chitosan and $\mathrm{DD}=78.54 \%$ for standard chitosan. A high degree of deacetylation indicates a large amount of free amino groups present in the molecule, which, in acidic solution, are protonated and may form favorable electrostatic interactions with other molecules, an example of which is the $\mathrm{SO}^{3-}$ groups of the structure of azo dyes [30-32].

In studies of crystallinity, microbiological chitosan showed a high crystallinity (crystallinity index $=$ $55.96 \%$ ) and standard chitosan was seen to be amorphous, suggesting a lower amount of intermolecular structural links between the amino groups of residues in the standard chitosan when compared with microbiological chitosan [29,33]. During the process of transforming $\alpha$-chitin into chitosan, some very careful steps must be taken so as not to degrade the polymer chain, thus generating an amorphous chitosan [34,35]. This does not happen when chitosan is formed by the specific action of chitin deacetylase under the $\gamma$-chitin in fungi. The high degree of crystallinity is also described as favoring the adsorption of acid dyes by chitosan [36].

In the analysis of viscosimetric molecular weight, the microbiological chitosan showed a low molecular weight, while standard chitosan showed an average viscosimetric molecular weight. The importance of molecular weight on coagulation-flocculation process is noted in the literature which states that the lower molecular weight of chitosan is related to the increased efficiency in removing azo dyes in systems where the solvent has a low ionic strength (distilled water) [31].

After selecting the culture medium for the low-cost production of chitosan, production was scaled up to obtain satisfactory amounts of chitosan to be used to evaluate its application in removing AO7, which was used in this study as a dye model for treating from textile effluents .

\subsection{Initial Considerations}

The literature describes the use of chitosan obtained from the exoskeleton of crustaceans, as an alternative to the chemical treatment of wastewater, and shows that some factors such as the concentration of chitosan in solution, the type of chemical pollutant, $\mathrm{pH}$, the type and concentration of dye and ionic strength of the solution are significant variables in the adsorption process by chitosan [19,23-25,37,38]. In this paper, the importance of microbiological chitosan as an alternative substance for discoloring textile wastewater was first tested by CCRD (see Table 1).

The coagulant-flocculant action, at first, was influenced by the origin and physico-chemical characteristics of chitosan and by the ionic strength of the water used as solvent (Table 1), and obtained up to $89.91 \%$ and $73.54 \%$ decolorization efficiency for the microbiological and standard chitosans, respectively. In order to analyse the isothermal equilibrium, the literature suggests using the Langmuir model to describe the adsorption of the dye by chitosan, indicating that the crosslink preferably occurs through the formation of a monolayer on the surface of particles of chitosan $[23,25,36,39]$. 
Table 1. Results of $2^{3}$ central complete rotational design (CCRD), with six axial points and four central points which show the efficiency in removing the orange acid 7 (AO7) from solutions by microbiological or standard chitosan (CS) in distilled or tap water. Data acquired after $2 \mathrm{~h}$ of incubation.

\begin{tabular}{|c|c|c|c|c|c|c|c|}
\hline \multirow{3}{*}{ Assay } & \multicolumn{3}{|c|}{ Independent variables } & \multicolumn{4}{|c|}{$\begin{array}{rr}\text { Discoloration } \\
\end{array}$} \\
\hline & \multirow{2}{*}[\mathrm{CS}]{} & \multirow{2}{*}{ [dye] } & \multirow{2}{*}{$\mathbf{p H}$} & \multicolumn{2}{|c|}{ Microbiological CS } & \multicolumn{2}{|c|}{ Standard CS } \\
\hline & & & & Distilled water $^{\dagger *}$ & Tap water ${ }^{*}$ & Distilled water ${ }^{*}$ & Tap water ${ }^{*}$ \\
\hline 1 & -1 & -1 & -1 & $70.91 \mathrm{a}$ & 58.21 & 56.95 & 49.58 \\
\hline 2 & 1 & -1 & -1 & $75.45 b$ & 61.21 & 45.54 & 51.58 \\
\hline 3 & -1 & 1 & -1 & $34.90 \mathrm{c}$ & $\underline{80.32 j}$ & 68.21 & 71.53 \\
\hline 4 & 1 & 1 & -1 & $76.62 b$ & 73.39 & 67.57 & 68.50 \\
\hline 5 & -1 & -1 & 1 & $55.31 \mathrm{~d}$ & 58.36 & 56.43 & 45.42 \\
\hline 6 & 1 & -1 & 1 & $58.63 d$ & 61.1 & 52.37 & 53.21 \\
\hline 7 & -1 & 1 & 1 & $33.35 \mathrm{c}$ & 70.69 & 63.39 & $\underline{72.031}$ \\
\hline 8 & 1 & 1 & 1 & $\underline{89.91 \mathrm{e}}$ & 72.66 & 67.68 & 71.68 \\
\hline 9 & -1.68 & 0 & 0 & $\overline{14.91 \mathrm{f}}$ & 32.23 & $\underline{72.841}$ & 71.79 \\
\hline 10 & 1.68 & 0 & 0 & $66.18 \mathrm{~g}$ & 68.23 & 62.17 & 67.03 \\
\hline 11 & 0 & -1.68 & 0 & $71.27 \mathrm{a}$ & 52.88 & 38.46 & 40.04 \\
\hline 12 & 0 & 1.68 & 0 & $56.67 d$ & $\underline{80.6 \mathrm{j}}$ & 64.88 & 73.571 \\
\hline 13 & 0 & 0 & -1.68 & $85.28 \mathrm{~h}$ & 72.48 & 68.48 & 67.21 \\
\hline 14 & 0 & 0 & 1.68 & $80.57 \mathrm{i}$ & 66.27 & 63.87 & 55.53 \\
\hline $15 *$ & 0 & 0 & 0 & $75.26 \mathrm{bi}$ & 62.20 & 62.94 & 65.12 \\
\hline
\end{tabular}

\subsection{Factorial Analysis}

2.3.1. Effect of the Origin and Physicochemical Characteristics of Chitosan on the Coagulation-Flocculation of AO7

In the study of the main effects of the chitosan standard (Sigma), it was observed that for the systems where the solvent was distilled water there was a significant result $(p<0.05)$ for the factors of chitosan concentration and dye concentration, which enabled the variance analysis and showed the efficiency of the decolorization by using the response surface methodology (Figure 1). The result was not significant for the range of $\mathrm{pH}$, for the parameters considered, which may be for the reasons suggested by Wang et al. [7] and Focher et al. [33]: most of the amino groups of the amorphous chitosan are shown to be protonated, independently of the $\mathrm{pH}$ in solution.

Figure 1 shows that the efficiency in removing AO7 was greater when there was a low concentration of standard chitosan and in the range of $60-80 \mathrm{mg} / \mathrm{L}$ of dye. It is suggested that the amorphous condition of standard chitosan may have favored accessibility to the amino sites of the polymer $[7,29,31,33]$ up to a limit, when the concentration of dye saturated the system and there was a need to increase the concentration of chitosan so that the efficiency of removing AO7 from the solution was further improved. 
Figure 1. The 3D-surface plot (left) and 2D-projection (right) showing the interactions between standard chitosan concentration and dye concentration at $\mathrm{pH} 3.0$ on discoloration efficiency in distilled water.
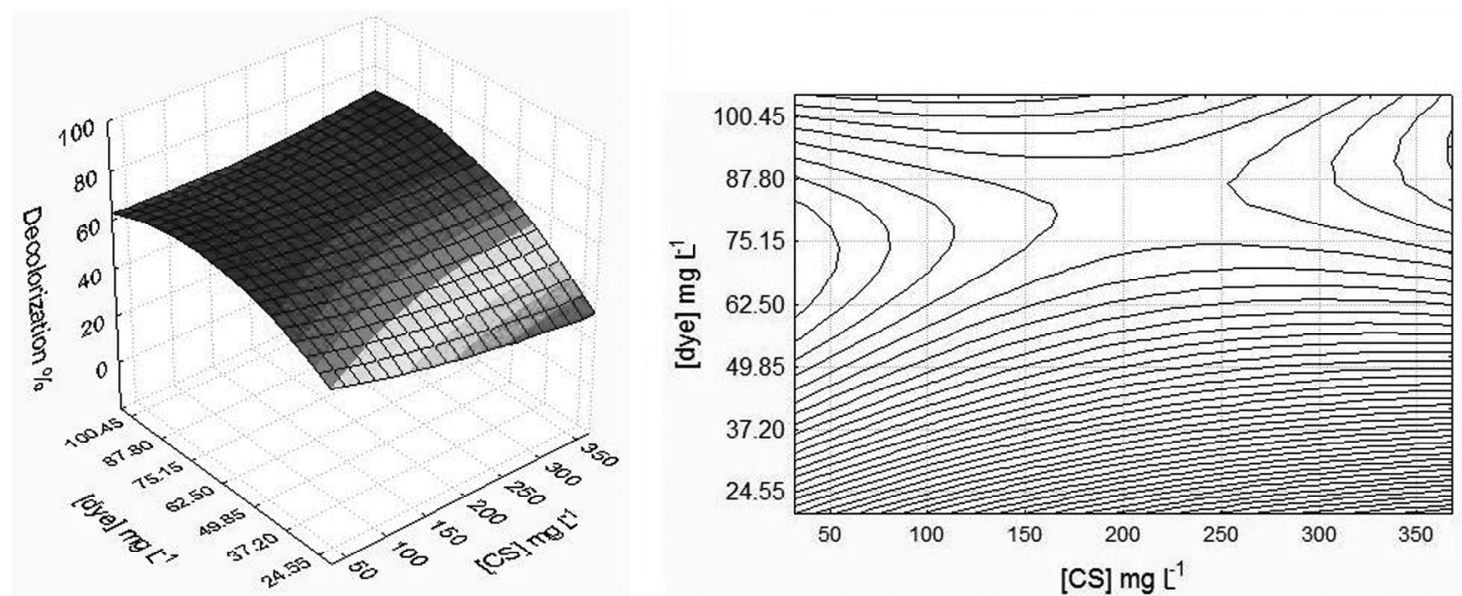

In systems where microbiological chitosan was added in distilled water, only the concentration factors of chitosan and the concentration of dye were significant $(p<0.01)$ for representation in a quadratic model. Using the response surface generated by the model (Figure 2), one can obtain the conditions of chitosan and dye concentration that resulted in a greater removal of AO7 from the solution, for which an optimum range of $180-280 \mathrm{mg} / \mathrm{L}$ was observed for the concentration of chitosan and 24.55 to $73.58 \mathrm{mg} / \mathrm{L}$ for the concentration of dye. The significance of the result for microbiological chitosan, when compared to the removal efficiency of standard chitosan in distilled water, can be observed by means of the Tukey test (Table 1). The greater efficiency in removing AO7, up to 89.91\%, by microbiological chitosan in comparison with standard chitosan is suggested by the higher degree of deacetylation (DD) and the high crystallinity shown by microbiological chitosan [31], which corroborates data given by Wong et al. [36], who state that an amorphous condition of chitosan reduces the adsorption capacity for acid dyes. Another possible influence on the greater efficiency in removing the dye by microbiological chitosan its lower molecular weight compared with standard chitosan $[31,40]$.

Figure 2. The 3D-surface plot (left) and 2D-projection (right) showing the interactions between microbiological chitosan concentration and dye concentration at $\mathrm{pH} 3.0$ on decoloration efficiency in distilled water.
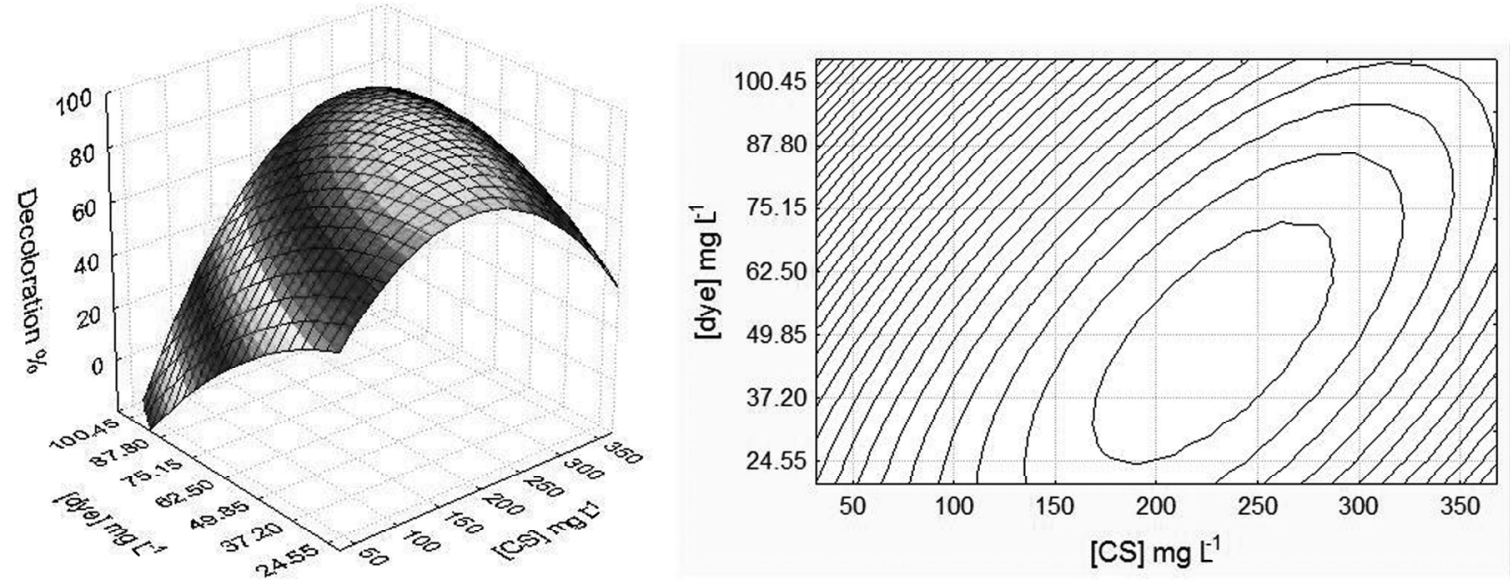
Although, no significant main effect was observed for the factor $\mathrm{pH}$ in systems where the solvent was distilled water, what can be stressed is that there is a linearity between the amount of microbiological chitosan required to be bound to the dye and the $\mathrm{pH}$ value of the solution (Figure 3 ). This fact can be explained by the solvent properties of the chitosan, which, in acid $\mathrm{pH}$, presents mostly $\mathrm{NH}^{3-}$ reactive sites, thus enabling the formation of electrostatic bonds in a larger amount than in systems where the $\mathrm{pH}$ is closer to the neutral value [7,31,32]. Szygula et al. [19] also observed that the lower the $\mathrm{pH}$ value the less the amount of chitosan that is required to bind with the reactive sites of the azo dye AB92 (acid blue 92).

Figure 3. The 2D-projections showing the interactions between microbiological chitosan concentration and dye concentration at different $\mathrm{pH}$ evaluated by CCRD in distilled water.

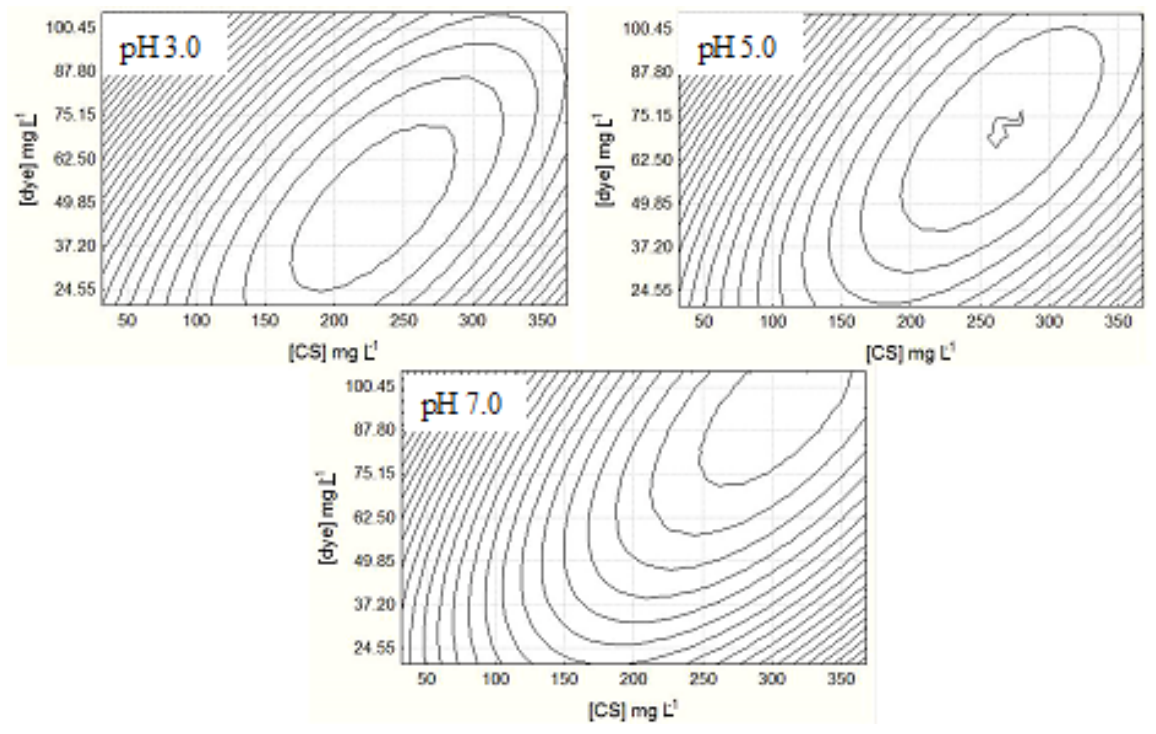

To analyze the effects of the ionic strength of the solvent on the systems where microbiological or standard chitosan were added, a complete factorial design was carried out both on distilled water and tap water.

In the assays where microbiological chitosan was applied, significant differences $(p<0.05)$ were observed when the ionic strengths of the solvent were compared on the removal of AO7, as observed by the Tukey test (Table 1). It is suggested that the high degree of deacetylation and low molecular weight of microbiological chitosan were important characteristics for the greater efficiency in removing AO7 in distilled water [31], since the ionic strength of the solvent may have interfered with the sorption mechanism between the protonated amino groups of chitosan and the anions of the dye [30,32].

In the tests for applying standard chitosan, it can be observed from the Tukey test that there were no significant differences dependent on the ionic strength of the solvent, and this suggests that the amorphous condition of the molecule of the standard chitosan has favored the formation of electrostatic bonds between the chitosan and AO7 regardless of the ionic strength. For systems where standard or microbiological chitosan was applied, in tap water, the only significant effect was for the dye concentration factor, thus making it impossible to apply this factor to equational modeling so as to assess the main effects or interactions. 


\subsubsection{Analysis of the Effects of the Ionic Strength of the Solvent in Removing AO7 by Chitosan}

The difference from the influence of the tap water used in the study by Szygula et al. [19] is suggested, mainly, on account of the difference in the ion composition observed for the two kinds of water, particularly because of the amount of sulfate ions $\left(\mathrm{SO}^{-2}\right)$, which was suggested as influential in the process of removing the azo dye Acid Blue 92 (AB92). However, the tap water used in this experiment had a low sulfate concentration (data not shown), which can be differentiated in the results obtained. The physico-chemical properties of the chitosans are another factor suggested as important for explaining the difference in the results.

Although a higher removal efficiency of $\mathrm{AO} 7$, up to $89.91 \%$, was observed due to the action of microbiological chitosan in distilled water, the high cost of using distilled water at industrial levels suggests the use of microbiological chitosan in systems where the solvent may have to be tap water. The suggestion arises from the fact that regardless of the ionic strength of the solvent, microbiological chitosan showed higher efficiency in removing AO7, when compared with standard chitosan (chitosan obtained from crustaceans) (Table 1).

2.3.3. Modeling for the Removal Percentage of AO7 by Microbiological Chitosan in Solvent of Low Ionic Strength

The general quadratic model was used to explain the higher removal percentage of AO7 by microbiological chitosan in a solution of low ionic strength (distilled water) for the range of values selected in this study:

$$
Y=\beta 0+\sum \beta j x j+\sum \beta i x i x j+\sum \beta j j x j 2
$$

where $\mathrm{Y}$ is the predicted response, $\beta 0$ is the offset term, $\beta \mathrm{i}$ is the linear displacement, is the square $\beta \mathrm{ii}$ is the quadratic offset, $\beta \mathrm{ij}$ is the effect of the interaction, $\mathrm{i}<\mathrm{j}$, and $\mathrm{xi}$ is the non-dimensional coded value of $\mathrm{Xi}[41]$.

In Table 1, assay 8 showed a significantly higher decolorization percentage value, up to $89.91 \%$, when compared to other conditions. Response Y predictions for the percentage of decolorization for assay 8 was obtained from Equation (1).

$$
\begin{aligned}
& \text { Ydecol. }(\%)=78.36+14.09 \times 1-3.66 \times 2-2.09 \times 3-13.31 \times 12-5.01 \times 22+11.30 \times \\
& 12+5.52 \times 23
\end{aligned}
$$

The statistical significance of the prediction response equation was certified by the $\mathrm{F}$ test and by variance analysis (ANOVA). The ANOVA (data not shown) of the quadratic regression model demonstrated that the model was significant, having a value $p<0.01$ and $\mathrm{R}^{2}=0.983$, thus demonstrating the applicability of the model when the experiment is projected.

\subsection{Recovery of the AO7 Dye Using the Flocculant Agent}

The recovery of the dye from the particles of microbiological and standard chitosan used during the experiments, in both distilled or tap water, was performed by solubilizing the flocculant agent in $30 \mathrm{~mL}$ of $0.1 \mathrm{M} \mathrm{NaOH}$ per sample of the agent obtained after carrying out each assay [19]. From this analysis it was possible to recover and concentrate in volume ten times smaller, approximately $95 \%$ of the dye 
used, regardless of type of chitosan or of the ionic strength of the solvent. Similar results were obtained by Szygula et al. [19] where approximately $100 \%$ of the azo dye bound to chitosan, obtained from crustacean, was recovered. Studies on reusing chitosan (microbiological or standard) dissociated from the dye were not possible due to the small amount used in CCRD. It is suggested that future studies consider conducting tests for re-microbiological chitosan with a view to reducing the cost of the process for removing azo dye from solutions.

\section{Experimental}

\subsection{Microorganism and Culture Media}

Sub-cultures of Syncephalastrum racemosum (WFCC/UCP-0148), grown on Potato Dextrose Agar (PDA, Oxoid, Kansas city, USA) at $28^{\circ} \mathrm{C}$ for $120 \mathrm{~h}$ were stored and used to make the spore solutions. For biomass production, $S$. racemosum was grown in an aerated environment (150 rpm) for $120 \mathrm{~h}$. The culture media were formulated from corn steep liquor (CSL) as the sole source of carbon and nitrogen, in accordance with full $2^{4}$ factorial designs with three central points (Table 2). For the formulation of culture media a concentrate of CSL was diluted in distilled water $(\mathrm{v} / \mathrm{v})$ in the proportions described in Table 1. Fermentation was performed in a 1,000 mL Erlenmeyer flask, containing $400 \mathrm{~mL}$ of culture medium. The chitosan produced was extracted according to $\mathrm{Hu}$ et al. [42]. After selecting the best production condition by full factorial design, the fermentation processes were scaled to a $2,800 \mathrm{~mL}$ Erlenmeyer flask, containing 1,200 mL of culture medium. Full factorial design was performed in duplicate and analyzed using the Statistica 7.0 software [43]. The statistical significance of the results was tested at $p<0.05$ level.

Table 2. $2^{4}$ Full factorial design, with three central points. Coded (CD) and uncoded (UCD) values to assess the main effects of independent variables on chitosan production.

\begin{tabular}{cccc}
\hline Independent Variables & CD (UCD) & CD (UCD) & CD (UCD) \\
\hline $\mathrm{CSL}$ & $-1(2 \%)$ & $0(6 \%)$ & $1(10 \%)$ \\
$\mathrm{pH}$ & $-1(4.0)$ & $0(6.0)$ & $1(8.0)$ \\
Temperature & $-1\left(25^{\circ} \mathrm{C}\right)$ & $0\left(31^{\circ} \mathrm{C}\right)$ & $1\left(37^{\circ} \mathrm{C}\right)$ \\
Size of inoculums & $-1\left(10^{2}\right.$ spores $\left./ \mathrm{mL}\right)$ & $0\left(5 \times 10^{5} \mathrm{spores} / \mathrm{mL}\right)$ & $1\left(10^{6}\right.$ spores $\left./ \mathrm{mL}\right)$ \\
\hline
\end{tabular}

$\mathrm{CSL}=$ corn steep liquor.

\subsection{Characterization of Corn Steep Liquor and Chitosan}

To conduct a percentage analysis of total carbohydrate and total nitrogen we used the methodologies described by Cunniff [44] and Kjeldahl [45], respectively.

The degree of deacetylation (DD) of chitosan was determined by infrared spectroscopy and calculated by Equation 2 [46]. The crystallinity index was calculated as per Equation (3) [33]:

$$
\begin{aligned}
& \mathrm{DD}(\%)=[100(\mathrm{Abs} 1655 / \mathrm{Abs} 3450)] / 1.33 \\
& \text { Crystallinity index }(\%)=100\{[\mathrm{I}(\theta \mathrm{c})-\mathrm{I}(\theta \mathrm{a})] / \mathrm{I}(\theta \mathrm{c})\}
\end{aligned}
$$

where I $(\theta \mathrm{c})$ is the relative intensity of the crystalline $\left(2 \theta=20^{\circ}\right)$ and I $(\theta \mathrm{a})$ corresponds to amorphous regions $\left(2 \theta=12^{\circ}\right)$ for chitosan. 
The molecular weight of chitosan was estimated by viscometry as per the methodology proposed by Terbojevich and Cosani [47]. The measurement was made from the average of the solutions of chitosan (0.3-0.6) in 1\% acetic acid, always carried out in triplicate. For this procedure, an Ubbelohde viscometer (Model B806 0C, Cannon Instrument Company, State College, PA, USA) was used.

\subsection{Azo Dye Solutions}

The azo dye, acid orange 7 (C.I. 15510; molecular weight $350.33 \mathrm{~g} / \mathrm{mol}$ ), also known as Orange II, is a monoazo compound with a reactive sulfonic group and negative loads in aqueous solution (Figure 1a). It was obtained from Sigma-Aldrich Corporation (St. Louis, MO, USA) and used without purification. To standardize the experiments, an acid orange 7 (AO7) stock solution was made $\left(5 \mathrm{mg} \mathrm{mL}^{-1}\right)$ and then diluted (v/v) as per Table 3.

Table 3. Central composite rotational design (CCRD), $2^{3}$ with six axial points and four central points was used to analyse the flocculant-coagulant action of chitosan (CS). The same CCRD was used to assess the action of microbiological and standard chitosan in distilled water or tap water. Coded (CD) and uncoded (UCD) values are given in the Table.

\begin{tabular}{cccccc}
\hline Factors & CD (UCD) $-\boldsymbol{\alpha}$ & CD (UCD) & CD (UCD) & CD (UCD) & CD (UCD) $+\boldsymbol{\alpha}$ \\
\hline$[\mathrm{CS}]$ & $-1.68(32 \mathrm{mg} / \mathrm{mL})$ & $-1(100 \mathrm{mg} / \mathrm{mL})$ & $0(200 \mathrm{mg} / \mathrm{mL})$ & $1(300 \mathrm{mg} / \mathrm{mL})$ & $1.68(368 \mathrm{mg} / \mathrm{mL})$ \\
{$[\mathrm{dye}]$} & $-1.68(20 \mathrm{mg} / \mathrm{mL})$ & $-1(37 \mathrm{mg} / \mathrm{mL})$ & $0(62.5 \mathrm{mg} / \mathrm{mL})$ & $1(88 \mathrm{mg} / \mathrm{mL})$ & $1.68(105 \mathrm{mg} / \mathrm{mL})$ \\
pH & $-1.68(1.6)$ & $-1(3.0)$ & $0(5.0)$ & $1(7.0)$ & $1.68(8.3)$ \\
\hline
\end{tabular}

Factors $=$ Independent variables.

\subsection{Chitosan Solutions}

Commercial chitosan, described as chitosan obtained by alpha-chitin, was used during the experiments as a comparative standard (Sigma-Aldrich) and dissolved in acetic acid without purification. The microbiological chitosan used in the coagulation-flocculation experiments was obtained from $S$. racemosum grown in the best condition selected by the full factorial design described in Table 2 and used without purification. The chitosans (Figure 4b) were ground and sieved, after which $1 \mathrm{~mm}$ size fractions were collected and used to prepare the coagulant solutions. The stock solutions of coagulant $(1 \% \mathrm{w} / \mathrm{v})$ were dissolved in $1 \%$ acetic acid $(\mathrm{v} / \mathrm{v})$ and then stored for use in all experiments.

Figure 4. (a) Chemical structure of azo dye acid Orange 7 (AO7); (b) Chemical structure of chitosan and possible intermolecular bonds.

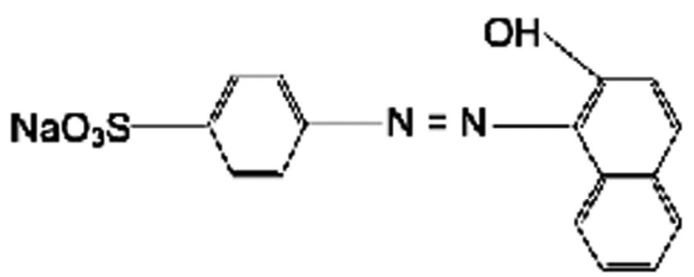

a

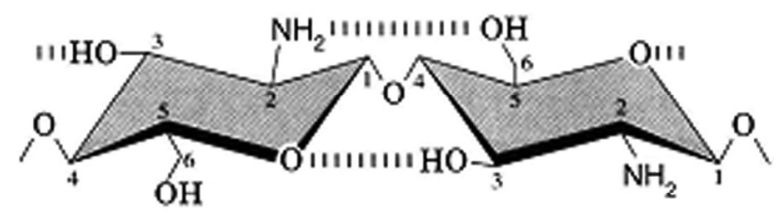

Chitosan - Possible intermolecular bonds 


\subsection{Coagulation-Flocculation Experiments}

To assess the main effects and interactions between the independent factors (chitosan concentration, dye concentration and initial $\mathrm{pH}$ ) in the process of coagulation-flocculation of the dye AO7 by standard and microbiological chitosan, a $2^{3}$ Central Composite Rotational Design (CCRD), with six axial points and four central points (Table 3 ) was proposed. The interference factors were determined in accordance with the literature [18,19,24]. Cestari et al. [24] described the temperature factor as statistically not interfering with the mechanisms of coagulation-flocculation by chitosan. The experiments were performed in random order so as to evaluate the experimental errors properly [48].

Homogeneous solutions of the dye were separated into beakers, each containing $300 \mathrm{~mL}$. The $\mathrm{pH}$ of each solution was measured and adjusted to a fixed value. After such adjustment, different volumes of chitosan solution ( $1 \% \mathrm{v} / \mathrm{v})$ were added (depending on the condition described in Table 3 ).

The experiments of coagulation-flocculation of the dye by chitosan were performed as per Roussy et al. [49] and Szygula et al. [19] with some modifications. The experiments were performed at room temperature $\left(26^{\circ} \mathrm{C} \pm 1.0^{\circ} \mathrm{C}\right)$. The samples collected were centrifuged at $12,240 \times \mathrm{g}$ for $20 \mathrm{~min}$ and filtered. The amount of dye retained on the membrane was negligible (less than $1.5 \%$ ).

\subsection{Decolorization Assay}

The collected samples were filtered and read upon dye absorption (485 nm) using a Genesis Spectronic UV-vis spectrophotometer, model 2 (Spectronic Instruments Inc., San Francisco, CA, USA). The percentage of decolorization was calculated by Equation (4):

$$
\text { Decolorization }(\%)=100((\mathrm{~T} 0-\mathrm{T} 2 \mathrm{H}) / \mathrm{T} 0)
$$

where $\mathrm{T} 0$ is the dye concentration in the initial phase of the experiment and $\mathrm{T} 2 \mathrm{H}$ is the dye concentration after $2 \mathrm{~h}$ of the experiment. The amount of dye removed from the solution was assumed as the total bound to the total quantity of chitosan present in the mixture.

\section{Conclusions}

In this study the tested concentrations of Orange AO7 ranged from 20 to $105 \mathrm{mg} / \mathrm{mL}$. The concentrations chosen for the tests were intended to demonstrate the ability of chitosan, a non-toxic polymer that degrades easily in the environment, as a substitute for expensive processes that are potentially toxic to aquatic organisms present in the environment. Based on the results obtained, it is noticed that chitosan was capable of removing up to $80.32 \%$ of dye present in tap water in situations where a concentration of $88 \mathrm{mg} / \mathrm{mL}$ is dependent on the conditions tested in only $2 \mathrm{~h}$ of incubation. Additional analyses associated with the use of "acetosyringone" laccase to oxidize low concentrations of AO7 (17.52 mg/L) at non-toxic levels have been described in the literature [50], but the efficiency procedures using microorganisms for removing azo dye are better at low concentrations of AO7 [51], thus demonstrating the need to pre-treat water contaminated with microbiological azo dye using chitosan to reduce levels of dye in the water to levels that are non-toxic to microorganisms.

The high efficiency removal of different concentrations of AO7 tested by microbiological chitosan rather than crustacean chitosan suggests this microbiological polymer is an economic and eco-friendly 
alternative that can be applied to the discoloration of wastewater. The low cost of producing high quality microbiological chitosan by Syncephalastrum racemosum in wastewater from industrial food industries further reduces the cost of removing $\mathrm{AO} 7$ from wastewater from the dyeing industry.

Despite the fact the removal of AO7 by microbiological chitosan in distilled water compared with the efficiency in tap water was more efficient, the high cost to industry of using distilled water suggests the use of microbiological chitosan in systems where tap water is a solvent. The high percentage recovery of $\mathrm{AO} 7$ from the microbiological chitosan particles used during the CCRD experiments favors the reuse of this biopolymer.

\section{Acknowledgments}

The authors are grateful to a local company in Pernambuco, Corn Products for having kindly provided the corn steep liquor for this study; to CAPES for a PhD scholarship; to FINEP and CNPq for financial support and to the Catholic University of Pernambuco (UNICAP) for all support laboratories.

\section{Conflict of Interest}

The authors declare no conflict of interest.

\section{References}

1. Campana-Filho, S.P.; Britto, D.; Curti, L.; Abreu, F.R.; Cardoso, M.B.; Battisti, M.V.; Sim, P.C.; Goy, R.C.; Signini, R.; Lavall, R.L. Extraction, Structures and properties of $\alpha$ - and $\beta$-chitin. Quim. Nova 2007, 30, 644-650.

2. Kent, P.W. Chitin and Mucosubstances. In Comparative Biochemistry; Florkin, M., Mason, H.S., Eds.; Academic Press Inc.: New York, NY, USA, 1964; pp. 93-136.

3. Kafetzopoulos, D.; Martinou, A.; Bouriotis, V. Bioconversion of chitin to chitosan: Purification and characterization of chitin deacetylase from Mucor. rouxii. Proc. Natl. Acad. Sci. USA 1993, 90, 2564-2568.

4. Campos-Takaki, G.M. The fungal versatility on the co-polymers. In Chitin and Chitosan; Dutta P.K., Ed.; Opportunities \& Challenges: Midnapore, India, 2005; pp. 69-94.

5. Muzzarelli, R.A.A. Chitin; Pergamon Press: New York, NY, USA, 1977; pp. 155-181.

6. Silva, M.C.F.; Barros Neto, B.; Stamford, T.C.M.; Campos-Takaki, G.M. Effect of environmental conditions on chitin and chitosan production by Cunninghamella. elegans UCP 542 using factorial design. Asian Chitin J. 2007, 3, 15-22.

7. Wang, W.; Dua, Y.; Qiu, Y.; Wang, X.; Hub, Y.; Yang, J.; Cai, J.; Kennedy, J.F. A new green technology for direct production of low molecular weight chitosan. Carbohydr. Polym. 2008, 74, 127-132.

8. Cardoso, A.; Lins, C.I.M.; Santos, E.R.; Freitas Silva, M.C.; Campos-Takaki, G.M. Screening of culture media to biomass and chitosan production by Rhizopus. arrhizus. Asian Chitin J. 2011, 7, $75-82$. 
9. Batista, A.C.L.; Cardoso, A.; Santos, E.R.; Freitas Silva, M.C.; Silva, C.A.A.; Campos-Takaki, G.M. Influence of simultaneous factors on chitosan production by Syncephalastrum racemosum (UCP/WFCC0148) in corn steep liquor culture media. Asian Chitin J. 2011a, 7, 63-68.

10. Cardoso, A.; Lins, C.I.M.; Santos, E.R.; Freitas Silva, M.C.; Campos-Takaki, G.M. Microbial enhance of chitosan production by Rhizopus. arrhizus using agroindustrial substrates. Molecules 2012, 17, 4904-4914.

11. Amorim, R.S.V.; Ledingham, W.M.; Kennedy, J.F.; Campos-Takaki, G.M. Chitosan from Syncephalastrum racemosum using sugar cane substrates as inexpensive carbon sources. Food Biotechnol. 2006, 20, 43-53.

12. Roberts, G.A.F. Chitin Chemistry; Macmillan: London, UK, 1992; pp. 167-172.

13. Abram, A.P.; Higuera, I. Quitina y Quitosano: Obtencion, Caracterizacion y Aplicaciones; Fondo Editorial: Lima, Peru, 2004; pp. 25-65.

14. Abdou, E.S.; Nagy, K.S.A.; Elsabee, M.Z. Extraction and characterization of chitin and chitosan from local sources. Biores. Technol. 2008, 99, 1359-1367.

15. Amorim, R.V.S.; Souza, W.; Fukushima, K.; Campos-Takaki, M.G. Faster chitosan production by Mucorelean strains in submerged culture. Braz. J. Microbiol. 2001, 32, $20-23$.

16. Inácio, R.G.S.; Freitas Silva, M.C.; Okada, K.; Campos-Takaki, G.M. Evaluation of chitin and chitosan production by Rhizopus. arrhizus UCP 402 mediated by dibenzothiophene (DBT). Asian Chitin J. 2009, 5, 11-18.

17. Hamano, P.S.; Kilikian, B.V. Production of red pigments by Monascus. ruber in culture media containing corn steep liquor. Braz. J. Chem. Eng. 2006, 23, 443-449.

18. Evangelista-Barreto, N.S.; Albuquerque, C.D.; Vieira, R.H.S.F.; Campos-Takaki, G.M. Cometabolic Decolorization of the Reactive Azo Dye Orange II by Geobacillus. stearothermophilus UCP 986. Text. Res. J. 2009, 79, 1266-1273.

19. Szygu1a, A.; Guibal, E.; Palacín, M.A.; Ruiz, M.; Sastre, A.N. Removal of an anionic dye (Acid Blue 92) by coagulation-flocculation using chitosan. J. Environ. Manag. 2009, 90, 2979-2986.

20. Baldrick, P. The safety of chitosan as a pharmaceutical excipient. Regul. Toxicol. Pharmacol. 2010, 56, 290-299.

21. Zhu, H-Y.; Fu, Y-Q.; Jiang, R.; Yao, J.; Xiao, L.; Zeng, G-M. Novel magnetic chitosan/poly(vinyl alcohol) hydrogel beads: Preparation, Characterization and application for adsorption of dye from aqueous solution. Bioresour. Technol. 2012, 105, 24-30.

22. Dotto, G.L.; Moura, J.M.; Cadaval, T.R.S.; Pinto, L.A.A. Application of chitosan films for the removal of food dyes from aqueous solutions by adsorption. Chem. Eng. J. 2013, 214, 8-16.

23. Cestari, A.R.; Vieira E.F.S.; Mota, J.A. The removal of an anionic red dye from aqueous solutions using chitosan beads - The role of experimental factors on adsorption using a full factorial design. J. Hazard Mater. 2008a, 160, 337-343.

24. Cestari, A.R.; Vieira, E.F.S.; Tavares, A.M.G.; Bruns, R.E. The removal of the indigo carmine dye from aqueous solutions using cross-linked chitosan-Evaluation of adsorption thermodynamics using a full factorial design. J. Hazard Mater. 2008b, 153, 566-574.

25. Cheung, W.H.; Szeto, Y.S.; McKay, G. Enhancing the adsorption capacities of acid dyes by chitosan nano particles. Bioresour. Technol. 2009, 100, 1143-1148. 
26. de Beer, J.O.; Vandenbroucke, C.V.; Massart, D.L.; de Spiegeleer, B.M. Half-fraction and full factorial designs versus central composite design for retention modelling in reversed-phase ion-pair liquid chromatography. J. Pharm. Biomed. Anal. 1996, 14, 525-541.

27. Bartnicki-Garcia, S.; Nickerson, W.J. Nutrition, Growth, And morphogenesis of Mucor. rouxii. J. Bacteriol. 1962, 84, 841-846

28. Fang, T.J.; Liao, B.-C.; Lee, S.-C. Enhanced production of xylanase by Aspergillus. carneus M34 in solid-state fermentation with agricultural waste using statistical approach. New Biotechnol. 2010, 27, 25-32.

29. Aranaz, I.; Mengíbar, M.; Harris, R.; Paños, I.; Miralles, B.; Acosta, N. Functional Characterization of Chitin and Chitosan. Curr. Chem. Biol. 2009, 3, 203-230.

30. Chiou, M.-S.; Ho, P.-Y.; Li, H.-Y. Adsorption of anionic dyes in acid solutions using chemically cross-linked chitosan beads. Dyes Pigm. 2004, 60, 69-84.

31. Guibal, E.; Van Vooren, M.; Dempsey, B.A.; Roussy, J. A review of the use of chitosan for the removal of particulate and dissolved contaminants. Sep. Sci. Technol. 2006, 41, 2487-2514.

32. Srinivasan, A.; Viraraghavan, T. Decolorization of dye wastewaters by biosorbents: A review. J. Environ. Manag. 2010, 91, 1915-1929.

33. Focher, B.; Beltrame, P.L.; Naggi, A.; Torri, G. Alkaline N-deacetylation of chitin enhanced by flash treatments. Reaction kinetics and structure modifications. Carbohydr. Polym. 1990, 12, 405-418.

34. Rege, P.R.; Block, L.H. Chitosan processing: influence of process parameters during acidic and alkaline hydrolysis and effect of the processing sequence on the resultant chitosan's properties. Carbohydr. Res. 1999, 321, 235-245.

35. Sukwattanasinitt, M.; Zhu, H.; Sashiwa, H.; Aiba, S. Utilization of commercial non-chitinase enzymes from fungi for preparation of 2-acetamido-2-deoxy-glucose from [beta]-chitin. Carbohydr. Res. 2002, 337, 133-137.

36. Wong, Y.C.; Szeto, Y.S.; Cheung, W.H.; McKay, G. Effect of temperature, particle size and percentage deacetylation on the adsorption of acid dyes on chitosan. Adsorption 2008, 14, 11-20.

37. Batista, A.C.L.; Villanueva, E.R.; Amorim, R.V.S.; Tavares, M.T.; Campos-Takaki, G.M. Chromium (VI) Ion Adsorption Features of Chitosan Film and Its Chitosan/Zeolite Conjugate 13X Film. Molecules 2011, 16, 3569-3579.

38. Dai, J.; Ren, F.-L.; Tao, C.-Y. Adsorption of $\mathrm{Cr}(\mathrm{VI})$ and Speciation of $\mathrm{Cr}(\mathrm{VI})$ and $\mathrm{Cr}(\mathrm{III})$ in Aqueous Solutions Using Chemically Modified Chitosan. Int. J. Environ. Res. Public Health 2012, 9, 1757-1770.

39. Guibal, E.; Touraud, E.; Roussy, J. Chitosan interactions with metal ions and dyes: Dissolvedstate vs. solid-state application. World J. Microbiol. Biotechnol. 2005, 21, 913-920.

40. Huang, C.; Chen, S.; Pan, J.R. Optimal condition for modification of chitosan: A biopolymer for coagulation of colloidal particles. Water Res. 2000, 34, 1057-1062.

41. Feng, Y.-L.; Li, W.-Q.; Wu, X.-Q.; Cheng, J.-W.; Ma, S.-Y. Statistical optimization of media for mycelial growth and exo-polysaccharide production by Lentinus. edodes and a kinetic model study of two growth morphologies. Biochem. Eng. J. 2010, 49, 104-112.

42. Hu, K-J.; Yeung, K.W.; Ho, K.P.; Hu, J.L. Rapid extraction of high-quality chitosan from mycelia of Absidia. glauca. J. Food Biochem. 1999, 23, 187-196. 
43. StatSoft, Inc. 2004, STATISTICA (data analysis software system), version 7. Available online: http://www.statsoft.com (accessed on 27 June 2007).

44. Method 958.06. In Official Methods of Analysis of AOAC International; Cunniff, P., Ed.; Association of the official Agriculatural Chemists (AOAC) International: Arlington, VA, USA, 1995; p. 21.

45. A guide to Kjeldahl Nitrogen determination methods and apparatus - Protecting your laboratory environment - Labconcq. Available online: http://www.expotechusa.com/catalogs/labconco/pdf/ KJELDAHLguide.PDF (accessed 06 July 2008).

46. Moore, G.K.; Roberts, G.A.F. Determination of the degree of N-acetylation of chitosan. Int. J. Biologic. Macromol. 1980, 2, 115-116.

47. Terbojevich, M.; Cosani, A. Molecular weight determination of chitin and chitosan, In Chitin Handbook; Muzzarelli, R.A.A., Peter, M.G., Eds.; Atec: Grottammare, Italy, 1997; pp. 87-101.

48. Box, G.P.G.; Hunter, J.S.; Hunter, W.G. Statistics for Experimenters: Design, Innovation and Discovery; John Wiley \& Sons: New York, NY, USA, 2005.

49. Roussy, J.; Van Vooren, M.; Dempsey, B.A.; Guibal, E. Influence of chitosan characteristics on the coagulation and the flocculation of bentonite suspensions. Water Res. 2005, 39, 3247-3258.

50. Molina-Guijarro, J.M.; Pérez, J.; Muñoz-dourado, J.; GuillÉN, F.; Moya, R.; Hernández, M.; Arias, M.E. Detoxification of azo dyes by a novel $\mathrm{pH}$-versatile, salt-resistant laccase from Streptomyces ipomoea. Int. Microbiol. 2009, 12, 13-21.

51. Garg, S.K.; Tripathi, M. Process parameters for decolorization and biodegradation of orange II (Acid Orange 7) in dye-simulated minimal salt medium and subsequent textile effluent treatment by Bacillus cereus (MTCC 9777) RMLAU1. Environ. Monit. Assess. 2013, doi:10.1007/s10661013-3223-2.

Sample Availability: Not available.

(C) 2013 by the authors; licensee MDPI, Basel, Switzerland. This article is an open access article distributed under the terms and conditions of the Creative Commons Attribution license (http://creativecommons.org/licenses/by/3.0/). 